\title{
Clinicopathological Features of Patients Diagnosed with Both Primary Thyroid Cancer and Primary Renal Cell Cancer and Its Comparison with Patients with Thyroid Cancer or Renal Cell Cancer Alone
}

\author{
Jun Park ${ }^{1}$, Young Nam Kim ${ }^{2}$, Hyunsoo Ryoo ${ }^{3}$, Hyunju Park ${ }^{1}$, So Young Park, \\ Tae Hyuk Kim ${ }^{1}$, Jae Hoon Chung, ${ }^{1}$ Seong II Seo ${ }^{3}$ and Sun Wook Kim ${ }^{1}$ \\ Division of Endocrinology \& Metabolism, Department of Medicine, Thyroid Center, Samsung Medical Center, Sungkyunkwan \\ University School of Medicine1, Seoul, Department of Medicine, Paju Hospital, Gyeonggi Provincial Medical Center ${ }^{2}$, Paju, \\ Department of Urology, Samsung Medical Center, Sungkyunkwan University School of Medicine', Seoul, Division of Endocrinolgy, \\ Department of Medicine, Korea University Ansan Hospital ${ }^{4}$, Ansan, Korea
}

Background and Objectives: Thyroid cancer (TC) and renal cell carcinoma (RCC) display more frequent co-occurrence than would be expected by chance. We investigated clinicopathological features of patients with both primary TC and primary RCC (TC/RCC) group to facilitate a greater understanding of the relationship between two cancers. Materials and Methods: A total of 53 patients who diagnosed with TC/RCC were enrolled. 13,663 TC-alone and 3279 RCC-alone patients who had undergone surgery at Samsung Medical Center between 1994 and 2014 were included as control groups. The clinicopathological characteristics of these patients were retrospectively reviewed. Results: The median age at the time of TC or RCC diagnosis was 54 years in TC/RCC group and the RCC-alone group, while the patients in TC-alone group were significantly younger (47 years). The TC/RCC group showed a nearly equal sex prevalence ( $49 \%$ male), significantly different than the results of the TC-alone group ( $80 \%$ female) and RCC-alone group ( $71 \%$ male). A higher grade of pathologic stage ( $56.6 \%$ in stage 3) and greater number of patients with multifocality of thyroid tumors (45 vs. $32 \%$ ), and more family history of cancer (32 vs. 0.4\%) were revealed in TC/RCC group than in TC-alone group. In addition, $15.1 \%$ of patients in TC/RCC group presented with additional primary cancers such as prostate, colon, stomach, breast, and lung cancers. Conclusion: Patients in the TC/RCC group have a high rate of cancer family history, multifocality of thyroid tumors, and additional cancers. To understand this unique subset group, additional studies for environmental and genetic factors would be helpful for earlier diagnosis of combined cancers.

Key Words: Thyroid cancer, Renal cell carcinoma, Second malignancy, Risk

\section{Introduction}

Thyroid cancer (TC) is a rapidly increasing carcinoma worldwide, and the most commonly diagnosed cancer due to early detection and increased diagnosis in Korea. ${ }^{1}$ It usually occurs in younger women at a mean age of around 45 years, with approximately $80 \%$ to $95 \%$ of all TC cases found to include papillary thyroid carcinoma. ${ }^{1,2)}$ Renal cell carcinoma (RCC) is the most

Received December 21, 2020 / Revised February 9, 2021 / Accepted February 10, 2021

Correspondence: Sun Wook Kim, MD, PhD, Division of Endocrinology \& Metabolism, Department of Medicine, Thyroid Center, Samsung Medical Center, Sungkyunkwan University School of Medicine, 115 Irwon-ro, Gangnam-gu, Seoul 06351, Korea Tel: 82-2-3410-1653, Fax:82-2-6918-4653,E-mail: swkimmd@skku.edu 
common type of kidney cancer and accounts for $2 \%$ to $3 \%$ of all adult malignancies. ${ }^{3)}$ Men are two to three times more likely to develop RCC than women and about $70 \%$ to $85 \%$ of cases of sporadic RCC are clear-cell RCC. ${ }^{4)}$

Previous studies have reported that patients with TC are at an increased risk of second primary malignancies and, conversely, patients with other malignancies also showed an increased risk of subsequent primary $\mathrm{TC}^{2,5-11)}$ Ronckers et al. ${ }^{2)}$ reported that patients had a $42 \%$ elevated risk of second primary TC after any kind of malignancy and, reciprocally, an $11 \%$ increase in secondary malignancies after TC. The highest risk for second TCs after first malignancy as well as secondary malignancies after initial TC was apparent in the first year after initial diagnosis. However, renal, breast, and prostate cancers presented persistently elevated risks and the association between TC and these specific cancers is bidirectional and positive. ${ }^{2)}$ Out research team previously reported that the overall risk of a second primary malignancy among patients with $\mathrm{TC}$ is increased by $6 \%$ in all sites except the stomach and cervix by using data from the Korea Central Cancer Registry. In addition, the greatest elevated risks were shown in cancers of the salivary gland, kidney, prostate, lung, and breast in order. ${ }^{8)}$ Similar results were reported in other studies. An analysis of findings in surveillance, epidemiology, and end results (SEER) database suggested that the most commonly elevated subsequent malignancies after TC include salivary gland and kidney cancers. ${ }^{9}$ Another study using the SEER database determined that an elevated risk of TC as a second primary malignancy was consistently significant in patients with cancers of renal and breast. ${ }^{10)}$

In spite of many studies having reported an association between TC and RCC, only few studies to date have examined the specific subset of patients who develop both primary TC and primary RCC (abbreviated TC/RCC). Therefore, in this study, we examined the clinicopathological findings of individuals with TC/RCC group in comparison with those of patients diagnosed with either TC or RCC-alone group. Furthermore, we performed a subgroup analysis among the patients with TC/RCC according to the order of diagnosis to evaluate the incidence of and risk factors for the development of TC/RCC.

\section{Materials and Methods}

\section{Study Patients}

The TC/RCC group of patients was established using those given the codes C73.9 (TC) and C64.9 (RCC) of the International Classification of Diseases for Oncology, third edition seen at our institution between 1994 and 2014. A total of 63 patients were classified as having both codes $\mathrm{C73.9}$ and C64.9, but 10 patients were excluded from the study analysis due to follow-up loss right after diagnosis. Data were compiled by way of retrospective chart review.

As control groups, 15,957 patients with TC who had undergone thyroidectomy and 3342 patients with RCC who underwent nephrectomy at Samsung Medical Center between 1994 and 2014 were included. Data from the surgery patient database of Samsung Medical Center were retrospectively reviewed. A total of 2231 patients in the TC-alone group were excluded since they had incomplete data such as the date of diagnosis and pathologic information. All patients with TC/RCC were excluded from the TC-alone and RCCalone groups. Therefore, 53 patients were finally included into the TC/RCC group, 13,663 patients were finally included into the TC-alone group, and 3279 patients were finally included into the RCC-alone group. This study was approved by an Institutional Review Board (SMC-IRB 2019-05-155).

\section{Statistical Analysis}

To compare differences between the TC/RCC group and the TC-alone group and between the TC/RCC group and the RCC-alone group, the Mann-Whitney test for continuous variables and the chi-squared or Fisher's exact test for categorical variables were used. For subgroup analysis according to the order of diagnosis, one-way analysis of variance followed by Tukey's post-hoc test or the Kruskal-Wallis test followed by the Mann-Whitney post-hoc test was used 
for quantitative data, while Fisher's exact test was used for categorical data. All statistical analyses were performed using the Statistical Package for the Social Sciences version 25.0 software program (IBM Corp., Armonk, NY, USA). A p value of less than 0.05 was considered to be statistically significant.

\section{Results}

\section{Clinicopathological Features of Patients with TC/RCC in Comparison with Patients with TC-Alone or RCC-Alone}

Clinicopathological characteristics of the TC/RCC

Table 1. Clinicopathological features of TC in coexisting TC and RCC group and TC alone group

\begin{tabular}{|c|c|c|c|}
\hline TC characteristics & $\begin{array}{l}\text { TC and RCC } \\
n=53(0.4 \%)\end{array}$ & $\begin{array}{l}\text { TC alone } \\
n=13,663\end{array}$ & $p$ value \\
\hline \multicolumn{4}{|l|}{ Age, years } \\
\hline Mean $\pm S D$ & $53.6 \pm 11.7$ & $47.2 \pm 11.6$ & \\
\hline Median (IQR) & $54.0(17)$ & $47.0(16)$ & $<0.001$ \\
\hline Sex & & & $<0.001$ \\
\hline Male & $26(49.1)$ & $2,688(19.7)$ & \\
\hline Female & $27(50.9)$ & $10,975(80.3)$ & \\
\hline Family history of any cancer & $17(32.1)$ & $47(0.4)$ & $<0.001$ \\
\hline Tumor size, cm (range) & $0.9(0.2-4.0)$ & $0.8(0.05-13.0)$ & 0.164 \\
\hline Multifocality & $24(45.3)$ & $4,415(32.4)$ & 0.046 \\
\hline Pathologic stage* & & & 0.003 \\
\hline Stage 1 & $19(35.8)$ & $7,994(59.0)$ & \\
\hline Stage 2 & $0(0)$ & $171(1.3)$ & \\
\hline Stage 3 & $30(56.6)$ & $4,375(32.3)$ & \\
\hline Stage 4 & $4(7.5)$ & $1,014(7.5)$ & \\
\hline LN metastasis & $23(43.4)$ & $5,635(41.7)$ & 0.805 \\
\hline Distant metastasis & $1(1.9)$ & $102(0.7)$ & 0.330 \\
\hline Operation type & & & 0.081 \\
\hline TT $w /$ or $w / o$ CND & $42(79.2)$ & $8,640(64.5)$ & \\
\hline TT with MRND & $4(7.5)$ & $1,848(13.8)$ & \\
\hline Lobectomy & $7(13.2)$ & $2,902(21.7)$ & \\
\hline Others & $0(0)$ & $273(2.0)$ & \\
\hline Extrathyroidal extension & $32(60.4)$ & $11,749(86.0)$ & $<0.001$ \\
\hline Lymphatic invasion & $0(0)$ & $247(1.8)$ & 1.000 \\
\hline Vascular invasion & $0(0)$ & $318(2.3)$ & 0.637 \\
\hline Histologic subtype & & & 0.146 \\
\hline PTC & $49(92.5)$ & $13,183(96.9)$ & \\
\hline FTC & $3(5.7)$ & $278(2.0)$ & \\
\hline MTC & $1(1.9)$ & $119(0.9)$ & \\
\hline ATC & $0(0)$ & $21(0.2)$ & \\
\hline Others & 0 & $61(0.4)$ & \\
\hline RAl therapy & $39(73.6)$ & $9,073(66.2)$ & 0.182 \\
\hline Total RAl dose, mCi (range) & $100(30-550)$ & $100(20-1400)$ & 0.519 \\
\hline F/U duration of TC, months (range) & $60.8(4.9-163.7)$ & $73.5(0.1-681.3)$ & 0.078 \\
\hline
\end{tabular}

ATC: anaplastic thyroid cancer, CND: central neck dissection, F/U: follow up, FTC: follicular thyroid cancer, IQR: interquartile range, LN: lymph node, MRND: modified radical neck dissection, MTC: medullary thyroid cancer, PTC: papillary thyroid cancer, RAI: radioactive iodine, RCC: renal cell carcinoma, SD: standard deviation, TC: thyroid cancer, TT: total thyroidectomy, w/: with, w/o: without

Data available for family history of any cancer $(n=12,052)$, tumor size $(n=13,647)$, multifocality $(n=13,624)$, pathologic stage $(n=13,554)$, LN metastasis $(n=13,506)$, distant metastasis $(n=13,554)$, extrathyroidal extension $(n=13,404)$, lymphatic invasion $(n=13,582)$, vascular invasion $(n=13,577)$, RAl therapy $(n=8,731)$ in TC alone group.

*Staging according to the American Joint Committee on Cancer (AJCC) Thyroid Cancer Staging System $7^{\text {th }}$ edition. 
group were compared with those of the TC-alone group (Table 1) and the RCC-alone group (Table 2), respectively, to discern whether there were any unique features of TC/RCC group. The mean and median ages at diagnosis of TC in the TC/RCC group were 53.6 and 54 years, respectively, which were significantly older than the ages (mean: 47.2, median: 47 years) of patients with TC-alone $(p<0.001)$. In the TC/RCC group, the number of men and women was almost equal (ratio of men to women: 49.1 to $50.9 \%$ ), while the TC-alone group showed a predominance of women (80.3\%). Patients in the TC/RCC group were more likely to present a higher grade of pathologic stage $(56.6 \%$ in stage 3 vs. $59.0 \%$ in stage 1$)$ and more multifocality of thyroid tumors (45.3 vs. $32.4 \%$ ), and had more family history of cancer (32.1 vs. $0.4 \%$ ) compared to those of patients in TC-alone group. There were no differences in tumor size, lymph node and distant metastasis, lymphatic and vascular invasion, histological type, and radioactive iodine (RAl) therapy and dose. Extrathyroidal extension varied between the two groups, but this seems to be an incidental finding (Table 1).

Among 3279 total RCC patients, $1.6 \%$ developed a co-existing TC. The patients with TC/RCC were diagnosed of RCC at a mean of 53.1 years and a median of 54 years, similar to patients in the RCC-alone group (mean: 54 years and median: 54 years). RCC much more dominantly occurred in males $(70.8 \%)$ in RCCalone group while even sex distribution in TC/RCC

Table 2. Clinicopathological features of RCC in coexisting TC and RCC group and RCC alone group

\begin{tabular}{|c|c|c|c|}
\hline RCC characteristics & $\begin{array}{l}\text { TC and RCC } \\
n=53(1.6 \%)\end{array}$ & $\begin{array}{c}\text { RCC alone } \\
n=3,279\end{array}$ & $p$ value \\
\hline \multicolumn{4}{|l|}{ Age, years } \\
\hline Mean \pm SD & $53.1 \pm 11.7$ & $54.0 \pm 12.2$ & \\
\hline Median (IQR) & $54.0(18)$ & $54.0(18)$ & 0.662 \\
\hline Sex & & & 0.001 \\
\hline Male & $26(49.1)$ & $2,320(70.8)$ & \\
\hline Female & $27(50.9)$ & $959(29.2)$ & \\
\hline $\mathrm{BMI}\left(\mathrm{kg} / \mathrm{cm}^{2}\right)$ & $25.0 \pm 3.6$ & $24.8 \pm 3.2$ & 0.825 \\
\hline Tumor size, cm (range) & $3.7(0.9-16.0)$ & $3.8(0.2-32.0)$ & 0.853 \\
\hline Pathologic stage* & & & 0.554 \\
\hline Stage 1 & $41(77.4)$ & $2,440(75.0)$ & \\
\hline Stage 2 & $2(3.8)$ & $286(8.8)$ & \\
\hline Stage 3 & $7(13.2)$ & $399(12.3)$ & \\
\hline Stage 4 & $3(5.7)$ & $129(4.0)$ & \\
\hline LN metastasis & $1(1.9)$ & $59(1.8)$ & 0.622 \\
\hline Distant metastasis & $3(5.7)$ & $113(4.0)$ & 0.469 \\
\hline Nuclear grade & & & 0.875 \\
\hline Gr 1-2 & $21(42.0)$ & $1,389(43.1)$ & \\
\hline Gr 3-4 & $29(58.0)$ & $1,833(56.9)$ & \\
\hline Histologic subtype & & & 0.257 \\
\hline Clear cell & $50(94.3)$ & 2,731 (83.3) & \\
\hline Renal papillary cancer & $1(1.9)$ & $217(6.6)$ & \\
\hline Chromopobe & $2(3.8)$ & $239(7.3)$ & \\
\hline Others & $0(0)$ & $90(2.7)$ & \\
\hline Type of surgery & & & 0.497 \\
\hline Radical nephrectomy & $31(58.5)$ & $2,063(63.0)$ & \\
\hline Nephron sparing surgery & $22(41.5)$ & $1,226(37.0)$ & \\
\hline F/U duration of RCC, months (range) & $73.0(3.5-213.0)$ & $43.5(0.4-236.0)$ & $<0.001$ \\
\hline
\end{tabular}

BMI: body mass index, F/U: follow up, Gr: grade, IQR: interquartile range, LN: Iymph node, RCC: renal cell carcinoma, SD: standard deviation, TC: thyroid cancer

Data available for pathologic stage $(n=3,254)$, LN metastasis $(n=3,270)$, distant metastasis $(n=2,845)$, nuclear grade $(n=3,222)$, histologic subtype $(n=3,277)$, type of surgery $(n=3,273)$ in RCC alone group.

* Staging according to the American Joint Committee on Cancer (AJCC) Kidney Cancer Staging System $7^{\text {th }}$ edition. 
group. Except for sex distribution $(p<0.001)$, there were no significant differences in findings in the TC/RCC group regarding body mass index, tumor size, pathologic staging, $L N$ and distant metastasis, nuclear grade, and histological type relative to in the RCCalone group (Table 2).

Interestingly, we found that eight patients (15.1\%) of the TC/RCC group presented additional primary cancers, including two with colon cancers, two with prostate cancers, two with stomach cancers, one with breast cancer, and one with lung and prostate cancers.

Therefore, while the patients of the TC/RCC group did not have significant differences in pathological characteristics with the TC- or RCC-alone patients, they had more cancer family history and multifocality of thyroid tumors than the patients of the TC-alone group, and had a high proportion of triple primary cancer.

\section{Comparison of TC/RCC Group According to the Order of Diagnosis}

Subgroup analyses of the TC/RCC group were conducted according to the order of diagnosis. Overall, 24 patients (45.3\%) developed primary RCC followed by subsequent TC (RCC $\rightarrow$ TC group), 17 patients (32.1\%) had first primary TC prior to RCC (TC $\rightarrow$ RCC group), and 12 patients $(22.6 \%)$ had concomitant disease within one year of initial diagnosis ( $\mathrm{TC}=\mathrm{RCC}$ group). The baseline characteristics of the total and subgroups of the TC/RCC group are summarized in Table 3. The median ages at the time of diagnosis of TC and RCC were younger in the $T C=R C C$ group than in either the $\mathrm{RCC} \rightarrow \mathrm{TC}$ or TC $\rightarrow$ RCC group $(\mathrm{p}=0.014)$. There were no significant differences in sex, body mass index, smoking, alcohol, cancer family history, and time interval between TC and RCC, regardless of the order of diagnosis (Table 3). The clinicopathological features of patients with TC/RCC, including RAI therapy, were compared between the three groups listed in Tables 4 and 5.

\section{Discussion}

In previous studies, many researchers have reported the persistent two-way association between

Table 3. Characteristics of coexisting primary TC and RCC according to the sequence of diagnosis

\begin{tabular}{|c|c|c|c|c|c|}
\hline \multirow[b]{2}{*}{ Characteristics } & \multicolumn{5}{|c|}{ Both TC and RCC } \\
\hline & $\begin{array}{l}\text { Total } \\
n=53\end{array}$ & $\begin{array}{c}\text { RCC } \rightarrow \text { TC } \\
n=24(45.3 \%)\end{array}$ & $\begin{array}{c}T C=R C C \\
n=12(22.6 \%)\end{array}$ & $\begin{array}{c}\mathrm{TC} \rightarrow \mathrm{RCC} \\
\mathrm{n}=17(32.1 \%)\end{array}$ & $p$ value \\
\hline \multicolumn{6}{|l|}{ Age, years $(T C)$} \\
\hline Mean \pm SD & $53.6 \pm 11.7$ & $57.3 \pm 9.8$ & $44.6 \pm 10.6$ & $54.7 \pm 12.3$ & \\
\hline Median (IQR) & $54(17)$ & $60.0(12)$ & $46.0(15)$ & $60.0(16)$ & 0.014 \\
\hline \multicolumn{6}{|l|}{ Age, years (RCC) } \\
\hline Mean \pm SD & $53.1 \pm 11.7$ & $53.4 \pm 10.4$ & $44.4 \pm 10.3$ & $58.9 \pm 11.0$ & \\
\hline Median (IQR) & $54.0(18)$ & $55.5(17)$ & $46.0(14)$ & $63.0(16)$ & 0.004 \\
\hline Sex & & & & & 0.713 \\
\hline Male & $26(49.1)$ & $13(54.2)$ & $6(50)$ & $7(41.2)$ & \\
\hline Female & $27(50.9)$ & $11(45.8)$ & $6(50)$ & $10(58.8)$ & \\
\hline $\mathrm{BMI}\left(\mathrm{kg} / \mathrm{cm}^{2}\right)$ & $25.0 \pm 3.6$ & $24.9 \pm 2.7$ & $25.6 \pm 4.3$ & $24.5 \pm 4.4$ & 0.756 \\
\hline Smoking, $\mathrm{n}(\%)$ & $9(17)$ & $4(16.7)$ & $3(25.0)$ & $2(11.8)$ & 0.735 \\
\hline Alcohol, n (\%) & $14(26.4)$ & $6(25.0)$ & $3(25.0)$ & $5(29.4)$ & 0.763 \\
\hline Family history of any cancer & $17(32.1)$ & $7(29.2)$ & $3(25.0)$ & $7(41.2)$ & 0.647 \\
\hline $\begin{array}{l}\text { Time interval between } \\
\text { TC \& RCC, months (range) }\end{array}$ & $\begin{array}{c}39.2 \\
(0-140.6)\end{array}$ & $\begin{array}{c}43.7 \\
(12.4-126.7)\end{array}$ & $\begin{array}{c}1.8 \\
(0-11.5)\end{array}$ & $\begin{array}{c}44.0 \\
(13.4-140.6)\end{array}$ & $<0.001$ \\
\hline $\begin{array}{l}\mathrm{F} / \mathrm{U} \text { duration of } \mathrm{TC} \text {, months } \\
\text { (range) }\end{array}$ & $\begin{array}{c}60.8 \\
(4.9-163.7)\end{array}$ & $\begin{array}{c}57.1 \\
(7.5-149.4)\end{array}$ & $\begin{array}{c}56.1 \\
(4.9-137.2)\end{array}$ & $\begin{array}{c}66.5 \\
(21.5-163.7)\end{array}$ & 0.301 \\
\hline $\begin{array}{l}\mathrm{F} / \mathrm{U} \text { duration of RCC, months } \\
\text { (range) }\end{array}$ & $\begin{array}{c}73.0 \\
(3.5-213.0)\end{array}$ & $\begin{array}{c}104.0 \\
(52.2-213.0)\end{array}$ & $\begin{array}{c}66.2 \\
(15.3-113.8)\end{array}$ & $\begin{array}{c}29.1 \\
(3.5-84.7)\end{array}$ & $<0.001$ \\
\hline
\end{tabular}

BMI: body mass index, F/U: follow up, IQR: interquartile range, RCC: renal cell carcinoma, SD: standard deviation, TC: thyroid cancer 
Table 4. Clinicopathological characteristics of TC in patient with coexisting primary TC and RCC

\begin{tabular}{|c|c|c|c|c|c|}
\hline \multirow[b]{2}{*}{ TC characteristics } & \multicolumn{5}{|c|}{ Both $\mathrm{TC}$ and $\mathrm{RCC}$} \\
\hline & $\begin{array}{l}\text { Total } \\
n=53\end{array}$ & $\underset{n=24}{R C C} \rightarrow$ TC & $\begin{array}{c}\mathrm{TC}=\mathrm{RCC} \\
\mathrm{n}=12\end{array}$ & $\begin{array}{c}\mathrm{TC} \rightarrow \mathrm{RCC} \\
\mathrm{n}=17\end{array}$ & $p$ value \\
\hline Tumor size, cm (range) & $0.9(0.2-4.0)$ & $1.0(0.2-4.0)$ & $1.2(0.4-4.0)$ & $0.8(0.5-3.0)$ & 0.396 \\
\hline Multifocality & $24(45.3)$ & $12(50.0)$ & $6(50.0)$ & $6(35.3)$ & 0.604 \\
\hline Bilaterality & $18(34.0)$ & $10(41.7)$ & $4(33.3)$ & $4(23.5)$ & 0.525 \\
\hline Pathologic stage* & & & & & 0.572 \\
\hline Stage 1 & $19(35.8)$ & $6(25.0)$ & $6(50.0)$ & $7(41.2)$ & \\
\hline Stage 2 & $0(0)$ & $0(0)$ & $0(0)$ & $0(0)$ & \\
\hline Stage 3 & $30(56.6)$ & $16(66.7)$ & $5(41.7)$ & $9(52.9)$ & \\
\hline Stage 4 & $4(7.5)$ & $2(8.3)$ & $1(8.3)$ & $1(5.9)$ & \\
\hline LN metastasis & $23(43.4)$ & $10(41.7)$ & $7(58.3)$ & $6(35.3)$ & 0.455 \\
\hline Distant metastasis & $1(1.9)$ & $0(0)$ & $1(8.3)$ & $0(0)$ & 0.226 \\
\hline Operation type & & & & & 0.845 \\
\hline TT w/ or w/o CND & $42(79.2)$ & $20(83.3)$ & $8(66.7)$ & $14(82.4)$ & \\
\hline TT with MRND & $4(7.5)$ & $1(4.2)$ & $1(8.3)$ & $2(11.8)$ & \\
\hline Lobectomy & $7(13.2)$ & $3(12.5)$ & $3(25.0)$ & $1(5.9)$ & \\
\hline Extrathyroidal extension & $32(60.4)$ & $16(66.7)$ & $6(50.0)$ & $10(58.8)$ & 0.628 \\
\hline Lymphatic invasion & $0(0)$ & $0(0)$ & $0(0)$ & $0(0)$ & \\
\hline Vascular invasion & $0(0)$ & $0(0)$ & $0(0)$ & $0(0)$ & \\
\hline Histologic subtype & & & & & 0.558 \\
\hline PTC & $49(92.5)$ & $22(91.7)$ & $11(91.7)$ & $16(94.1)$ & \\
\hline FTC & $3(5.7)$ & $2(8.3)$ & $1(8.3)$ & $0(0)$ & \\
\hline MTC & $1(1.9)$ & $0(0)$ & $0(0)$ & $1(5.9)$ & \\
\hline RAl therapy & $39(73.6)$ & $17(70.8)$ & 7 (58.3) & $15(88.2)$ & 0.260 \\
\hline $\begin{array}{l}\text { Initial RAl dose, } \mathrm{mCi} \\
\text { (range) }\end{array}$ & $100(30-180)$ & $60(30-150)$ & $100(30-180)$ & $30(30-150)$ & 0.478 \\
\hline $\begin{array}{l}\text { Total RAl dose, } \mathrm{mCi} \\
\text { (range) }\end{array}$ & $100(30-550)$ & $60(30-280)$ & $130(30-550)$ & $100(30-450)$ & 0.520 \\
\hline
\end{tabular}

CND: central neck dissection, FTC: follicular thyroid cancer, LN: lymph node, MRND: modified radical neck dissection, MTC: medullary thyroid cancer, PTC: papillary thyroid cancer, RAl: radioactive iodine, RCC: renal cell carcinoma, TC: thyroid cancer, TT: total thyroidectomy, w/: with, w/o: without

*Staging according to the American Joint Committee on Cancer (AJCC) Thyroid Cancer Staging System $7^{\text {th }}$ edition.

TC and RCC. ${ }^{2,6-8,12,13)}$ Besides, there are several cancer sites that showed significantly elevated risks in both directions, not only the thyroid and kidney but also the salivary gland, breast, prostate, scrotum, and brain. ${ }^{2,8)}$ Liu et al. ${ }^{14)}$ reported the bidirectional associations of RCC with many other malignancies, such as lung, breast, prostate, bladder, thyroid, and adrenal gland cancer. Various factors, including genetic, environmental, and treatment-related effects, could influence the development of subsequent second primary cancers. From a genetic point of view, MET tyrosine receptor kinase mutations have been previously discovered in TC and papillary RCC. ${ }^{15,16)}$ The leucine-rich repeat kinase-2 (LRRK2), which cooperates with MET to promote tumor cell growth and survival, is also am- plified and overexpressed in papillary RCC and TC. ${ }^{17)}$ In addition, the 1157 missense variant of the checkpoint kinase 2 (CHEK2) gene is associated with increased risks of breast, colon, kidney, prostate, and TC. ${ }^{18,19)}$ These results were consistent with those of the current study; eight patients had additional primary cancers of the colon, prostate, stomach, breast, and lungs beyond TC and RCC. Even though they did not perform gene mutation studies, there seems to be a genetic correlation between them.

In some studies, for the treatment-related factors, RAl exposure in the treatment of TC may be associated with second primary cancer, while, in others, there was no relationship between radioisotope exposure and subsequent primary cancers. ${ }^{2,5,7,20,21)}$ In 
Characteristics of Coexisting TC and RCC

Table 5. Clinicopathological characteristics of RCC in patient with coexisting primary TC and RCC

\begin{tabular}{|c|c|c|c|c|c|}
\hline \multirow[b]{2}{*}{ RCC characteristics } & \multicolumn{5}{|c|}{ Both $\mathrm{TC}$ and $\mathrm{RCC}$} \\
\hline & $\begin{array}{l}\text { Total } \\
n=53\end{array}$ & $\begin{array}{c}\mathrm{RCC} \rightarrow \mathrm{TC} \\
\mathrm{n}=24\end{array}$ & $\begin{array}{c}T C=R C C \\
n=12\end{array}$ & $\begin{array}{c}\mathrm{TC} \rightarrow \mathrm{RCC} \\
\mathrm{n}=17\end{array}$ & $p$ value \\
\hline Tumor size, cm (range) & $3.7(0.9-16.0)$ & $3.9(1.7-16.0)$ & $2.7(1.3-7.0)$ & $4.5(0.9-13.0)$ & 0.186 \\
\hline Bilaterality & $2(3.8)$ & $2(8.3)$ & $0(0)$ & $0(0)$ & 0.493 \\
\hline Pathologic stage* & & & & & 0.744 \\
\hline Stage 1 & $41(77.4)$ & $17(70.8)$ & $11(91.7)$ & $13(76.5)$ & \\
\hline Stage 2 & $2(3.8)$ & $2(8.3)$ & $0(0)$ & $0(0)$ & \\
\hline Stage 3 & $7(13.2)$ & $4(16.7)$ & $1(8.3)$ & $2(11.8)$ & \\
\hline Stage 4 & $3(5.7)$ & $1(4.2)$ & $0(0)$ & $2(11.8)$ & \\
\hline LN metastasis & $1(1.9)$ & $1(4.2)$ & $0(0)$ & $0(0)$ & 1.000 \\
\hline Distant metastasis & $3(5.7)$ & $1(4.2)$ & $0(0)$ & $2(11.8)$ & 0.449 \\
\hline Nuclear grade & & & & & 0.060 \\
\hline Gr 1-2 & $21(42.0)$ & $13(56.5)$ & $5(45.5)$ & $3(18.8)$ & \\
\hline Gr 3-4 & $29(58.0)$ & $10(43.5)$ & $6(54.5)$ & $13(81.3)$ & \\
\hline Operation type & & & & & 0.348 \\
\hline Radical nephrectomy & $31(58.5)$ & $16(66.7)$ & $5(41.7)$ & $10(58.8)$ & \\
\hline Nephron sparing surgery & $22(41.5)$ & $8(33.3)$ & $7(58.3)$ & $7(41.2)$ & \\
\hline Vascular invasion & $2(3.8)$ & $0(0)$ & $1(8.3)$ & $1(5.9)$ & 0.295 \\
\hline Collecting system invasion & $1(1.9)$ & $0(0)$ & $0(0)$ & $1(5.9)$ & 0.547 \\
\hline Histologic subtype & & & & & 0.772 \\
\hline Clear cell & $50(94.3)$ & $23(95.8)$ & $12(100)$ & $15(88.2)$ & \\
\hline Renal papillary carcinoma & $1(1.9)$ & $0(0)$ & $0(0)$ & $1(5.9)$ & \\
\hline Chromophobe & $2(3.8)$ & $1(4.2)$ & $0(0)$ & $1(5.9)$ & \\
\hline
\end{tabular}

Gr: grade, LN: lymph node, RCC: renal cell carcinoma, TC: thyroid cancer

*Staging according to the American Joint Committee on Cancer (AJCC) Kidney Cancer Staging System $7^{\text {th }}$ edition.

this study, there was no significant differences in the percentage of patients who received RAI and the RAI dose regardless of the order of diagnosis in the TC/RCC group. However, the treatment-related effect of RAI might be overlooked in this study due to follow up period was relatively short (5-6 years).

The main aim of our study was to evaluate the unique characteristics of patients diagnosed with TC/RCC. We found significant differences existed in the age at diagnosis, sex distribution, cancer family history, multifocality and pathologic stage of TC between TC/RCC group and the TC-alone group. Moreover, one interesting unexpected finding was that $15.1 \%$ of patients of the TC/RCC group had at least tertiary primary malignancies. TC occurred predominantly in women with a mean age of 47.2 years in TC-alone group, whereas the TC/RCC group did not present a sex prevalence either way and the mean age at diagnosis of TC was much older (53.6 years). Patients in RCC-alone group and TC/RCC group were diagnosed with RCC at almost the same age and the composition of the RCC-alone group was predominantly male ( $70.8 \%$ vs. $49.1 \%$ in TC/RCC group). The TC/RCC group showed higher pathologic stages of TC (stage 1, 2, 3, and $4: 35.8 \%, 0 \%, 56.6 \%$, and $7.5 \%$, respectively) than the TC-alone group (stage 1, 2, 3, and $4: 59.0 \%, 1.3 \%, 32.3 \%$, and $7.5 \%$, respectively) $(\mathrm{p}=0.003)$, which seems to be derived by age; according to the American Joint Committee on Cancer/Union for International Cancer Control seventh edition staging system, patients with papillary or follicular TC younger than 45 years of age generally only have stages I and II. Cancer family history, tumor multifocality of thyroid tumors, and a high incidence of multiple primary cancers in the TC/RCC group strongly suggested a genetic effect in the association between TC and RCC. In the subgroup analysis, patients in the $\mathrm{TC}=\mathrm{RCC}$ group were significantly younger at the time of diagnosis of TC or RCC than those in the RCC $\rightarrow$ TC and TC $\rightarrow$ RCC groups but, unfortunately, we could 
not find any other significant differences in clinicopathological findings according to the order of diagnosis of TC/RCC. Additionally, although there is controversy as to whether RAl exposure increases the subsequent malignancies; based upon the present results, prior RAI therapy for TC seemed not to elevate the risk of developing second primary RCC.

To our knowledge, this is the second study to examine unique features of patients with TC/RCC. The age at diagnosis and sex distribution were consistent with the previous study. ${ }^{12)}$ The differences between the two studies were that there were more cases of TC before RCC (TC $\rightarrow$ RCC; 51\%, RCC $\rightarrow$ TC; $27 \%$ ) in the previous study, while there were more cases of RCC before TC (RCC $\rightarrow$ TC; $45.3 \%$, TC $\rightarrow$ RCC; $32.1 \%$ ) in the present study. In addition, the previous study showed that $43 \%$ of patients in the TC/RCC group had other additional cancers, especially most of them were women and breast cancer. In this study, $15.1 \%$ of them had other combined cancers, and the colon, prostate, stomach, breast and lung cancers were relatively evenly distributed. Therefore, although the percentages of multiple primary cancers in the two studies were different, the result that the TC/RCC group had a high ratio of three or more cancers was consistent. Additionally, cancer family history and multifocality were added as comparative variables in this study, and their meaningful differences were confirmed when comparing TC/RCC and TC-alone groups.

There are several limitations to this study. First, this was a retrospective study that may have possible selection bias. Second, it is presumed that the sample size of the TC/RCC group was small; thus, the difference between subgroups according to the order of diagnosis may not have been sufficient for statistical analysis. Third, we only studied the clinicopathologic characteristics rather than etiologic studies such as molecular tests of the tumors. Finally, in the RCCalone group, there was no data on cancer family history and multifocality, and also data on other combined cancers of TC-alone and RCC-alone groups were not available in this study. However, we hope this findings could serve as a basis for future studies to dig into the relevance between the two cancers.
In conclusion, the reason behind co-occurring TC and RCC is not clearly understood. We determined that patients with TC/RCC more often showed a cancer family history and multifocality of thyroid tumors than those with TC alone. In addition, 15\% of TC/RCC patients had additional malignancies. In order to understand the cause of TC and RCC together, further studies such as environmental and genetic factors for this group are needed. This understanding may help earlier diagnosis of combined cancers.

\section{Funding}

The authors have no funding.

\section{Conflicts of Interest}

No potential conflict of interest relevant to this article was reported.

\section{Orcid}

Jun Park: https://orcid.org/0000-0002-7873-1458

Young Nam Kim: https://orcid.org/0000-0002-2610-2879 Hyunsoo Ryoo: https://orcid.org/0000-0001-6707-6833 Hyunju Park: https://orcid.org/0000-0002-6010-5539 So Young Park: https://orcid.org/0000-0002-7973-5944 Tae Hyuk Kim: https://orcid.org/0000-0002-7975-2437 Jae Hoon Chung: https://orcid.org/0000-0002-9563-5046 Seong II Seo: https://orcid.org/0000-0002-9792-7798 Sun Wook Kim: https://orcid.org/0000-0002-6858-3439

\section{References}

1) Oh CM, Kong HJ, Kim E, Kim H, Jung KW, Park S, et al. National epidemiologic survey of thyroid cancer (NEST) in Korea. Epidemiol Health 2018;40:e2018052.

2) Ronckers CM, McCarron P, Ron E. Thyroid cancer and multiple primary tumors in the SEER cancer registries. Int $J$ Cancer 2005;117(2):281-8.

3) Bray F, Ferlay J, Soerjomataram I, Siegel RL, Torre LA, Jemal A. Global cancer statistics 2018: GLOBOCAN estimates of incidence and mortality worldwide for 36 cancers in 185 countries. CA Cancer J Clin 2018;68(6):394-424.

4) Patard JJ, Leray E, Rioux-Leclercq N, Cindolo L, Ficarra V, Zisman A, et al. Prognostic value of histologic subtypes in renal cell carcinoma: a multicenter experience. J Clin Oncol 2005; 
23(12):2763-71

5) Rubino C, de Vathaire F, Dottorini ME, Hall P, Schvartz $\mathrm{C}$, Couette JE, et al. Second primary malignancies in thyroid cancer patients. Br J Cancer 2003;89(9):1638-44.

6) Sandeep TC, Strachan MW, Reynolds RM, Brewster DH, Scelo G, Pukkala E, et al. Second primary cancers in thyroid cancer patients: a multinational record linkage study. J Clin Endocrinol Metab 2006;91(5):1819-25.

7) Brown AP, Chen J, Hitchcock YJ, Szabo A, Shrieve DC, Tward JD. The risk of second primary malignancies up to three decades after the treatment of differentiated thyroid cancer. J Clin Endocrinol Metab 2008;93(2):504-15.

8) Cho YY, Lim J, Oh CM, Ryu J, Jung KW, Chung JH, et al. Elevated risks of subsequent primary malignancies in patients with thyroid cancer: a nationwide, population-based study in Korea. Cancer 2015;121(2):259-68.

9) Kim C, Bi X, Pan D, Chen Y, Carling T, Ma S, et al. The risk of second cancers after diagnosis of primary thyroid cancer is elevated in thyroid microcarcinomas. Thyroid 2013;23(5): 575-82.

10) Lal G, Groff M, Howe JR, Weigel RJ, Sugg SL, Lynch CF. Risk of subsequent primary thyroid cancer after another malignancy: latency trends in a population-based study. Ann Surg Oncol 2012;19(6):1887-96.

11) Subramanian S, Goldstein DP, Parlea L, Thabane L, Ezzat $\mathrm{S}$, Ibrahim-Zada I, et al. Second primary malignancy risk in thyroid cancer survivors: a systematic review and meta-analysis. Thyroid 2007;17(12):1277-88.

12) Carhill AA, Litofsky DR, Sherman SI. Unique characteristics and outcomes of patients diagnosed with both primary thyroid and primary renal cell carcinoma. Endocr Pract 2015;21(5): 461-7.

13) Canchola AJ, Horn-Ross PL, Purdie DM. Risk of second primary malignancies in women with papillary thyroid cancer.
Am J Epidemiol 2006;163(6):521-7.

14) Liu H, Hemminki K, Sundquist J. Renal cell carcinoma as first and second primary cancer: etiological clues from the Swedish Family-Cancer Database. J Urol 2011;185(6):2045-9.

15) Wasenius VM, Hemmer S, Karjalainen-Lindsberg ML, Nupponen NN, Franssila K, Joensuu H. MET receptor tyrosine kinase sequence alterations in differentiated thyroid carcinoma. Am J Surg Pathol 2005;29(4):544-9.

16) Malchoff CD, Sarfarazi M, Tendler B, Forouhar F, Whalen G, Joshi V, et al. Papillary thyroid carcinoma associated with papillary renal neoplasia: genetic linkage analysis of a distinct heritable tumor syndrome. J Clin Endocrinol Metab 2000;85(5): 1758-64.

17) Looyenga BD, Furge KA, Dykema KJ, Koeman J, Swiatek PJ, Giordano TJ, et al. Chromosomal amplification of leucine-rich repeat kinase-2 (LRRK2) is required for oncogenic MET signaling in papillary renal and thyroid carcinomas. Proc Natl Acad Sci U S A 2011;108(4):1439-44.

18) Cybulski C, Huzarski T, Gorski B, Masojc B, Mierzejewski M, Debniak T, et al. A novel founder CHEK2 mutation is associated with increased prostate cancer risk. Cancer Res 2004;64(8):2677-9.

19) Cybulski C, Gorski B, Huzarski T, Masojc B, Mierzejewski $\mathrm{M}$, Debniak $\mathrm{T}$, et al. CHEK2 is a multiorgan cancer susceptibility gene. Am J Hum Genet 2004;75(6):1131-5.

20) Berthe E, Henry-Amar M, Michels JJ, Rame JP, Berthet P, Babin E, et al. Risk of second primary cancer following differentiated thyroid cancer. Eur J Nucl Med Mol Imaging 2004;31(5):685-91.

21) Chuang SC, Hashibe M, Yu GP, Le AD, Cao W, Hurwitz EL, et al. Radiotherapy for primary thyroid cancer as a risk factor for second primary cancers. Cancer Lett 2006;238(1): $42-52$. 